patients: a change in practice. Critical care nursing quarterly, 2012. 35(3): p. 247-254.

6. NPUAP, Pressure Injury Stages. 2016.

7. Huỳnh Văn Ân, M.T.T.B.D.v.c., Độ sâu thích hợp của ống nội khí quản qua đường miệng ở người
Việt Năm trưởng thành. 2006.

8. Nguyển Thị Châm, Đ.T.N., Pham Ngọc Thắng, Hoàng Thi Phương, Đánh giá hiêu quả ứng dung Anchor fast trong phòng loét tỳ đè liên quan đến nội khí quản. Tạp chí điều dưỡng Việt Nam, 2018.

\title{
THỰC TRANG CẤP CỨU CHẤN THƯƠNG TRƯỚC VIỆN QUA CÁC TRƯỜNG HỢP CHẤN THƯƠ'NG SỌ NÃO NĂNG DO TAI NẠN GIAO THÔNG CẤP CỨU TẠI BỆNH VIỆN VIẸTT ĐỨC
}

\section{TÓM TẮT.}

Đă̆t vấn đề: Cấp cứu trước viên (prehospital care), đặc biệt cấp cứu chấn thương quan trọng góp phần giảm nguy cơ biến chứng và tử vong, nhất là những trường hợp chấn thương so não (CTSN) do tai nan giao thông (TNGT). Chúng tồi thực hiện nghiên cứu đánh giá thực trạng cấp cứu trước viện để đề ra khuyến nghị. Đối tượng và phương pháp nghiên cứu: Tất cả bệnh nhẩn CTSN do TNGT được cấp cứu tại bệnh viện Việt Đức trong thời gian từ 31/12/2020 đến $31 / 3 / 2021$, không phân biệt giới, tuổi, địa phương và nghê, có hồ sơ đây đủ, bao gồm cả các ca năng vể và tử vong. Số liệu được xử lý phần mềm SPSS 20.0. Kêt quả: Tổng số 200 trường hợp cấp cứu CTSN nặng do TNGT, tuổi từ 21 - 60 chiếm 67,5\%, nam giới chiếm đa số 88,5\%; Thương tổn phối hợp: hàm mặt chiếm $44 \%$, chấn thương chi chiếm $23,5 \%$, chấn thương ngưo kín $22 \%$. Được cấp cứu ban đâuu tại cơ sở y tế chiếm tỷ lệ $96,5 \%$; Vận chuyển bằng xe cứu thương chiếm $98 \%$; nhân viển y tế đi cùng chiếm $97 \%$. Kỹ thuật đã làm: Ven truyền chiếm 97,5\%, NKQ và khai thông đường thở $85 \%$ và $84,5 \%$, nẹp cô $37,5 \%$. Xử trí tại viện: phẩu thuật cấp cứu chiếm $42 \%$. Kết quả xử lý: nặng xin về chiếm $24,5 \%$, tử vong chung chiếm $25 \%$. Kết luận và khuyến nghị: Các trường hợp cấp cứu CTSN do TNGT tại bệnh viện Việt Đức thời gian gân đây được tiếp cận cấp cứu trước viện, hầu hết bệnh nhân được xử trí ban đâuu tại cơ sở y tế và được vận chuyển xe cứu thương. Tuy nhiên tỷ lệ tử vong cò̀ cao, chúng tôi khuyến nghị cần tăng cường chất lượng cấp cứu trước viện nhất là với chấn thương sọ não.

Tư khoá: Chấn thương sọ não; Tai nạn thương tích, Chăm sóc trước viện.

\section{SUMMARY}

CURRENT TITUATION OF PREHOSPITAL CARE THROUGH THE BRAIN TRAUMATIC INJUFY DUE TO TRAFFIC ACCIDENT HAVE BEEN TREATED AT

\footnotetext{
1 Trường Đại học Thăng Long

${ }^{2}$ Bênh viện Hữu Nghi Viêt Đức

Chịu trách nhiệm chính: Đinh Văn Quỳnh

Email: quynhkbvd@gmail.com

Ngày nhận bài: 10.9.2021

Ngày phản biên khoa hoc: 28.10.2021

Ngày duyệt bài: 12.11.2021
}

\section{VIET DUC UNIVERSITY HOSPITAL}

Introductions: Prehospital care, especially trauma emergency is playing an important role to reduce morbidity and mortality, especially brain trauma related to traffic accident. We conducted a study through emergency cases at Viet Duc University Hospital aiming to assess the situation of prehospital care and to make recommendations. Materials and methods: All patients with brain trauma due to traffic accident have been treated at the hospital during the period from December 31, 2020 to March 31, 2021, regardless of gender, age, locality and profession, have complete records, including deaths. Data were processed using SPSS 20.0 software. Results: A total of 200 patients with severe brain trauma due to traffic accident were enrolled, age group from 21-60 years old accounted for $67.5 \%$, males in $88.5 \%$; Injuries associated were: maxillofacial trauma accounted for $44 \%$, limb injuries accounted for $23.5 \%$, chest trauma $22 \%$. The number of patients were provided the first aid at medical facilities accounted for $96.5 \%$; Transportation by ambulance accounted for 98\%; Medical staff accompanying patients while transporting accounted for $97 \%$. The procedures provided were IV accounted for $97.5 \%$, intubation and airway assessment with the rate of $85 \%$ and $84.5 \%$ respectively, collier for spine injury was in $37,5 \%$. The treatment on emergency at the hospital: $42 \%$ were operated on emergency. Treatment results: released to die accounted for $24.5 \%$, death in hospital $0.5 \%$, overall mortality was $25 \%$. Conclusions and recommendations: The study showed that brain trauma due to traffic accident at Viet Duc University Hospital, having access to prehospital care have improved, most of the patients were initially provided the first aid at the medical facilities and transported by ambulances. However, the mortality rate is still related high, we recommend strengthening the prehospital care especially with traumatic brain injury.

Keywords; Traumatic brain injury; Injury, Prehospital care.

\section{I. ĐẶT VẤN ĐỀ}

Tai nạn thương tích (TNTT) vẫn là vấn đề toàn cầu, nguyên nhân chủ yếu của các trường hợp bị TNTT và tử vong là tai nạn giao thông (TNGT), đặc biệt là tai nạn giao thông đường bộ (TNGTĐB). Cứ mỗi 6 giây có một trường hợp tử 
vong do TNTT trên toàn cầu. Hậu quả dẫn đến gánh nặng toàn cầu về bệnh tật tới $10 \%$, là nguyên nhân hàng đầu gây tử vong và tàn tật thanh thiếu niên. Đặc biệt các nước đang phát triển như Việt Nam tỷ lệ TNTT do TNGT vần cao và đứng đầu số ca cấp cứu tại bệnh biện. Theo Tổ chức $Y$ tế thế giới $(\mathrm{WHO})$ gánh nặng toàn cầu do thương tích chiếm đến $80 \%$ tại các nước có thu nhập trung bình và thấp (middle-income countries (LMICs) do tử vong do TNTT từ các nước này chiếm đến $90 \%$ tử vong toàn cầu. Tử vong do TNTT tại các nước có thu nhập trung bình và thấp gấp hơn 3 lần các nước có thu nhập cao $[1,2]$.

Tại Viêt Nam theo một báo cáo của Bộ Y tế năm 2012 cho thấy số nạn nhân TNGT đển cấp cứu tại bệnh viện chiếm $31,2 \%$ tổng số TNTT. Mặc dù sổ cấp cứu cao, tuy nhiên theo Bộ Y tế, năng lực cấp cứu TNGT chưa đáp ứng được yêu cầu thực tế nhất là các tuyến dưới và cấp cứu ban đầu. Báo cáo "Thống kê tử vong do tai nạn thương tích năm 2016" của Cục quản lý môi trường $Y$ tế cho thấy tử vong do TNGT chiếm tỷ lệ cao nhất với tỷ xuất là 16,53/100.000 dân. Trong tổng số 35.586 trường hợp tử vong do TNTT, tử vong do TNGT là 15.318, chiếm 43,0\%. Một trong những nguyên nhân do năng lực cấp cứu trước viện chấn thương có ảnh hưởng đến kết quả điều trị và làm tăng nguy cơ biến chứng và tử vong $[3,4]$.

Bệnh viện Việt Đức [5], trung tâm ngoai khoa tuyến cuối của cả nước mỗi năm cấp cứu trên 30,000 trường hợp TNTT, trong đó TNGT khoảng 18,000 trường hợp, mối năm mổ trên 70,000 trường hợp trong những năm gần đây. Các trường hợp phẫu thuật trong cấp cứu hầu hết là do TNTT, trong đó phần lớn là do TNGT. Tuy nhiên có một thực tế còn nhiều nạn nhân TNGT đến cấp cứu đã có biến chứng, hoặc tử vong do chưa được tiếp cận hoặc chưa được cấp cứu kịp thời và đúng cách, chuyển tuyển không cần thiết. Do vậy chúng tôi thực hiện nghiên cứu đánh giá thực trạng cấp cứu trước viện các nạn nhân TNGT tại bệnh viện Việt Đức nhẳm tìm hiểu các yếu tố liên quan góp phần nâng cao chất lượng điều trị bệnh nhân chấn thương.

\section{II. ĐỐI TƯƠNGG VÀ PHƯƠNG PHÁP NGHIÊN CỨU}

Đối tượng nghiên cứu. Tất cả bệnh nhân CTSN do TNGT được cấp cứu tại bệnh viện Việt Đức trong thời gian từ $31 / 12 / 2020$ đển 31/3/2021, không phân biệt giới, tuổi, địa phương và nghề, có hồ sơ đầy đủ, bao gồm cả các ca tử vong.
Các biến nghiên cứu gồm: Thông tin chung: tuổi, giới, địa phương, hình thức bị tai nạn giao thông, thời gian được tiếp cân y tế

Đặc điểm tổn thương. Đặc điểm cấp cứu ban đầu: nơi cấp cứu, các kỹ thuật cấp cứu ban đầu theo $A B C D E$.

Kết quả cấp cứu ban đầu, tử vong và nguyên nhân tử vong.

Tiêu chuẩn loại trừ: Bệnh nhân cấp cứu nhưng không do nguyên nhân TNTT

Bệnh nhân và gia đình từ chối cung cấp thông tin và phối hợp

Hồ sơ bệnh án không đây đủ

Địa điểm và thời gian nghiên cứu. Khoa khám bệnh cấp cứu Bệnh viện Hữu nghị Việt Đức Thời gian: như trên

Phương pháp nghiên cứu. Thiết kế mẫu hồ sơ nghiên cứu thu thập thông tin.

Nghiên cứu sử dụng thiết kế nghiên cứu mô tả, tiến cứu

Cỡ mẫu. Lãy mẫu thuận tiện. Toàn bộ bệnh nhân được lựa chọn nếu thỏa mãn các tiêu chuẩn kể trên.

\section{KẾT QUẢ NGHIÊN CỨU}

Tổng số 200 bệnh nhân cấp cứu CTSN do tai nạn giao thông được phân bổ như sau

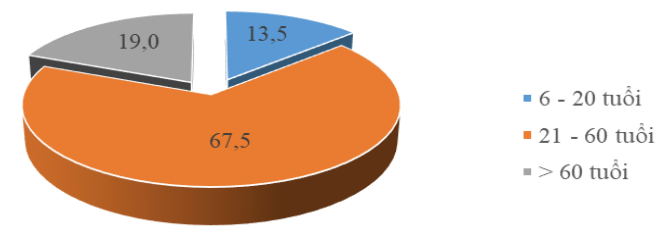

Biểu đồ 1. Phân bố theo nhóm tuổi

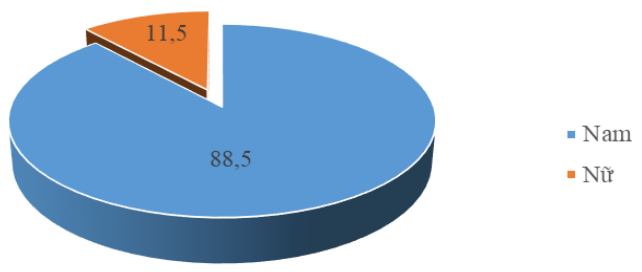

Biểu đồ 2. Phân bố theo giới

Nhận xét: Phần lớn bệnh nhân trong độ tuổi từ $21-60$ chiếm tỷ lệ $67,5 \%$, tuổi > 60 chỉ chiếm $19 \%$. Nam giới đa số chiếm tỷ lệ $88,5 \%$, nữ giới chỉ có $11,5 \%$. 
Bảng 1. Thương tổn phối hợp ( $N=200)$

\begin{tabular}{|c|c|c|}
\hline Thương tốn & $\mathbf{n}$ & $\mathbf{\%}$ \\
\hline Chẫn thương bụng kín & 20 & 10,0 \\
\hline Chấn thương ngực kín & 44 & 22,0 \\
\hline Chấn thương cột sống & 21 & 10,5 \\
\hline Chấn thương hàm mặt & 88 & 44,0 \\
\hline Chấn thương chi & 47 & 23,5 \\
\hline
\end{tabular}

Nhận xét: Thương tốn phối hợp chiếm tỷ lệ cao nhất là chấn thương hàm mặt $44 \%$, chấn thương chi 23,5\%, chấn thương ngực kín 22\%.

Bảng 2. Đặc điểm vận chuyển bệnh nhân $(N=200)$

\begin{tabular}{|c|c|c|c|}
\hline \multicolumn{2}{|c|}{ Đăc điểm vân chuyển } & $\mathbf{n}$ & $\%$ \\
\hline \multirow{2}{*}{$\begin{array}{c}\text { Đến cơ sở } \\
y \text { tế }\end{array}$} & $\begin{array}{c}\text { Đến cơ sở y tế } \\
\text { ban đầu }\end{array}$ & 193 & 96,5 \\
\hline & $\begin{array}{l}\text { Đến thẳng bênh } \\
\text { viện Việt Đức }\end{array}$ & 7 & 3,5 \\
\hline \multirow{2}{*}{$\begin{array}{l}\text { Phương } \\
\text { tiên vâan } \\
\text { chuyển } \\
\end{array}$} & Xe cứu thương & 196 & 98,0 \\
\hline & $\begin{array}{c}\text { Người nhà tự vận } \\
\text { chuyển }\end{array}$ & 4 & 2,0 \\
\hline \multirow{3}{*}{$\begin{array}{l}\text { Nhân viên } \\
\text { y tế đi } \\
\text { kèm }\end{array}$} & Bác sĩ & $\frac{2}{101}$ & 1,0 \\
\hline & Điều dưỡng & 194 & 97,0 \\
\hline & $\begin{array}{l}\text { Không có nhân } \\
\text { viền y tế }\end{array}$ & 4 & 2,0 \\
\hline
\end{tabular}

Nhận xét: Hầu hết được chuyển đến cơ sở y tế ban đầu chiếm tỷ lệ 96,5\%; vận chuyển chủ yếu bằng xe cứu thương chiếm $98 \%$; nhân viên y tế đi kèm chiếm tỷ lệ $97 \%$.

Bảng 3. Đặc điểm sơ cứu tuyến trước (N $=200)$

\begin{tabular}{|c|c|c|}
\hline Sơ cứu & $\mathbf{n}$ & $\mathbf{\%}$ \\
\hline Khai thông đường thở (A) & 169 & 84,5 \\
\hline Nẹp collier (D) & 75 & 37,5 \\
\hline Đặt nội khí quản (A) & 170 & 85,0 \\
\hline Bóp bóng (B) & 123 & 61,5 \\
\hline Epp tim (C) & 2 & 1,0 \\
\hline Đặt ven truyền (C) & 195 & 97,5 \\
\hline Bất động chi gãy (C) & 27 & 13,5 \\
\hline Băng câm máu (C) & 83 & 41,5 \\
\hline Không xừ trí gì & 5 & 2,5 \\
\hline
\end{tabular}

Nhận xét: Tỷ lệ các kỹ thuật xử lý ban đầu gồm $C, A, B$ chiếm tỷ lệ cao nhất gồm ven truyền chiếm tỳ lệ $97,5 \%$, sau đó là đặt NKQ và khai thông đường thở với tỷ lệ tương ứng là $85 \%$ và $84,5 \%$. Nẹp cổ tuy chiếm $37,5 \%$, rất quan trọng trong cấp cứu CTSN.

Bảng 4. Xử trí cấp cứu tại bệnh viện (N $=200)$

\begin{tabular}{|c|c|c|}
\hline Xử trí cấp cứu & $\mathbf{n}$ & $\mathbf{\%}$ \\
\hline Phâu thuật cấp cứu & 84 & 42,0 \\
\hline Vào viện theo dõi & 20 & 10,0 \\
\hline Diều trị hồi sức & 21 & 10,5 \\
\hline Chuyến viện & 20 & 10,0 \\
\hline Nặng xin về & 49 & 24,5 \\
\hline
\end{tabular}

\begin{tabular}{|c|c|c|}
\hline Tử vong & 1 & 0,5 \\
\hline Không đồng ý tiếp tục điều trị & 5 & 2,5 \\
\hline Tống & $\mathbf{2 0 0}$ & $\mathbf{1 0 0}$ \\
\hline
\end{tabular}

Nhân xét: Hầu hết được phẫu thuật trong cấp cứu với tỷ lệ $42 \%$. Kết quả có nă̆ng xin về chiếm $24,5 \%$, tử vong tại chỗ $0,5 \%$. Tử vong chung tại phòng cấp cứu chiếm 25\%.

\section{BÀN LUÂN}

Theo thống kê của Bộ Y tế năm 2018, cả nước có 1.226.704 trường hợp mắc tai nạn thương tích, trong đó có 9.745 trường hợp tử vong, chiếm tî lệ $0,73 \%$ so với tổng số mắc TNTT. Tử vong do TNGT vẫn là nguyên nhân hàng đầu, chiếm $47,91 \%$, tiếp theo là đuối nước $12,31 \%$, tự tử $11,45 \%$, tai nạn lao động 6,81\%. Việt Nam là một trong số các nước có tî lệ tử vong do TNTT cao trên thế giới. Nâng cao chất lượng sơ, cấp cứu được xác định là giải pháp quan trọng, góp phần giảm thiệt hại về người trong các vụ TNGT (Hội nghị tăng cường cấp cứu trước viện, Hà Nội, 2018)

Thực tế năng lực cấp cứu ban đầu hay cấp cứu trước viện (prehospital care) tai Việt Nam những năm qua đã có những thay đổi, tuy nhiên vẫn còn nhiều bất cập cần giải quyết. Theo một báo cáo về thực trạng cấp cứu tại hiện trường của Viện Quân y 103 năm 2005 cho thấy 91,9\% nạn nhân được cấp cứu do người đi đường, $3,2 \%$ được tự cấp cứu, và $4,9 \%$ được nhân viên y tế cấp cứu. Trong khi đó, đánh giá về thực trạng chất lượng sơ cấp cứu ban đầu tại Bệnh viện Việt Đức cho thấy $5,5 \%$ cố định xương và $7,2 \%$ cầm máu chưa đúng kỹ thuật. Trong một nghiên cứu của JICA (2009), băng vết thương đạt yêu cầu $61,2 \%$ (kín và không chảy máu) và $38,8 \%$ có băng nhưng không đạt yêu câu (không kín và vẫn chảy máu), cố định gãy xương có $51,4 \%$ đạt yêu cầu (hai đâu xương gãy không di chuyển được) và không đạt yêu cầu là $48,6 \%$. Bên cạnh đó, năng lực của hệ thống cấp cứu 115 cũng còn hạn chế về nguồn lực và trang thiết bi $[3,5,6]$

Trong báo cáo của chúng tôi cho thấy tổng số 200 trường hợp cấp cứu CTSN nặng do TNGT, tuổi từ $21-60$ chiếm $67,5 \%$, nam giới chiếm đa số $88,5 \%$ (biểu đồ 1 và biểu đồ 2); Thương tổn phối hợp: hàm mă̆t chiếm $44 \%$, chấn thương chi chiếm $23,5 \%$, chẩn thương ngực kín $22 \%$. Được cấp cứu ban đầu tại cơ sở y tế chiếm tỷ lệ 96,5\%; Vận chuyển bằng xe cứu thương chiếm $98 \%$; nhẩn viên y tế đi cùng chiếm $97 \%$. Kỹ thuật đã làm: đường truyền chiếm $97,5 \%$, đặt NKQ và kiểm soát đường thở $85 \%$ và $84,5 \%$. 
(bảng 1,2 và 3 ). Tuy chiếm $37,5 \%$ nhưng nẹp cổ trong CTSN cũng rất quan trọng và được thực hiện. Qua nghiên cứu cho thây việc cấp cứu trước viện đã được cải thiện rõ. Đặc biệt các kỹ thuật cấp cứu cơ bản cứu sống người bệnh gồm $A, B, C$ đã được thực hiện. Bên cạnh đó hầu hết người bệnh được vận chuyển bằng xe cứu thương, có nhân viên y tế kèm là những thay đổi đáng kể về cấp cứu trước viện hiện nay. So sánh những báo cáo trước đây đã có chuyển biến tích cực. Những báo cáo của Bộ $Y$ tế trước đây nguyên nhân bất cập về cấp cứu trước viện là do: Thứ nhất là ở Việt Nam chỉ có một số tỉnh, thành phố lớn có trung tâm cấp cứu 115 và các trung tâm này hiện nay mới chỉ đáp ứng được khoảng $20 \%$ các cuộc gọi cấp cứu tai nạn. Thứ hai là mạng lưới tình nguyện viên (tình nguyện viên chữ thập đỏ, cựu chiến binh, nhân viên y tế thôn bản, nhóm người có thể xuất hiên ngay tại hiện trường vụ tai nạn để tiến hành những kỹ năng cấp cứu cơ bản để cứu sống nạn nhân chưa được đào tạo về cấp cứu tai nạn thương tích và không được trang bi dụng cụ và trang thiết bị cần thiết, không nắm được những kỹ thuật cấp cứu đúng để di chuyển, cố định hay vận chuyển nạn nhân. Tỷ lệ cán bộ y tế được đào tạo về cẩp cứu chấn thương tại tuyến xã, phường là 22,2\% [3,6].

Dự án Tăng cường hệ thống chăm sóc chấn thương trước viện nhằm nâng cao kỹ năng sơ cấp cứu cho đội ngũ tình nguyện viên giai đoạn 2010-2011 do Cục quản lý môi trường Y tế chủ trì qua giám sát 3320 trường hợp TNTT tại cộng đồng thấy $61,1 \%$ các trường hợp được sơ cấp cứu đã được chuyển đến các cơ sở y tế; Kết quả thực hiện sơ cấp cứu của tình nguyện viên về cơ bản được đánh giá là tốt từ $91-99 \%$ các trường hợp. Do vây, mố hình tiếp tục được thực hiện để tiếp tục hồ trợ đánh giá hiệu quả sơ cấp cứu trước viện và duy trì mô hình chấn thương trước viện tại Thừa Thiên Huế [6]

Tố chức Y tế thế giới (WHO) khuyến cáo, yếu tố quan trọng nhất là cấp cứu cho người bị thương càng sớm càng tốt. Hầu hết tử vong xảy ra trong những giờ đầu tiên sau tai nạn do hệ thống hô hấp bị ảnh hưởng, đường thở bị tắc hoặc do bị mất nhiều máu, tất cả những vấn đề này đều có thể xử trí được nhờ sơ, cấp cứu. Nếu được sơ, cấp cứu kịp thời, nạn nhân tai nạn giao thông có thể giảm đáng kể tỷ lệ tử vong cũng như những biến chứng, chấn thương. Tuy vậy trong nghiên cứu của Bệnh viện Quân y 103, chỉ có $63,8 \%$ nạn nhân tai nạn giao thông được chuyển đến bệnh viện trong 6 giờ đầu, số còn lại đến sau 6 giờ, trong đó có 8,2\% đến bệnh viện sau 72 giờ $[3,6,7]$

Trong nghiên cứu của chúng tôi (bảng 4) cho thấy hầu hểt được phẫu thuật trong cấp cứu với tỷ lệ $42 \%$. Để có thể cấp cứu và thực hiện phẫu thuật, trước hết các bệnh nhân còn chỉ định phẫu thuật và có khả năng phục hồi. Đây cũng là bằng chứng cho thấy hiệu quả của cấp cứu ban đầu, nhất là đối với CTSN. Hầu hết các bệnh nhân được xử lý $A$ và $B$, hai qui trình này rất quan trọng đối với CTSN, nhất là CTSN nặng. Ngoài ra qui trình $D$ đối với cột sống cổ cũng được tuân thủ. Tuy vậy kết quả nghiên cứu cũng chỉ ra tử vong chung tại phòng cấp cứu chiếm $25 \%$. Một phân cũng do tổn thương quá nặng các trường hợp CTSN, nhất là CTSN do TNGT thường tổn thương rất nặng, máu tụ lớn, dập não và phù nề dẫn đến những rối loạn không hồi phục. Việc cấp cứu ban đầu không chỉ nhanh, kịp thời mà cần có chất lượng như đảm bảo thông khí, cung cấp oxy, chống phù não sớm hy vọng giảm được tỷ lệ tử vong [5,7].

\section{KẾT LUÂ̂N VÀ KHUYẾN NGH!}

Mô hình chăm sóc chấn thương trước viên nên được hoàn thiện và mở rộng đến các đối tượng như lái xe taxi, lái xe ô tô, đặc biệt là lái xe trong ngành y tế để biết cách sơ cứu cho nạn nhân khi gặp tai nạn trên đường... Hệ thống cấp cứu trước viện, trung tâm cấp cứu và vận chuyển 115 và phủ rộng tới các huyện, xã. Cơ sở vật chất và trang thiết bị, đào tạo nhân lực cho cấp cứu ban đầu đối với TNTT nói chung và TNGT nói riêng nên được đầu tư và nâng cấp. Nên lồng ghép chương trình cấp cứu ban đầu với quân dân $y$, phối hợp hoạt động của Hội chữ thập đỏ, hể thống điều hành, xử lý thông tin về cấp cứu đảm bảo tiếp cận nạn nhân nhanh nhất nên được xây dựng.

Trong đó lưu ý cấp cứu ban đầu chấn thương sọ não đối với nhân viên y tế các tuyến trước cần được tập huấn thường xuyên cũng như trang bị đầy đủ phương tiện thiết yếu nhằm giảm nguy cơ biến chứng và tử vong cao.

\section{TÀI LIÊU THAM KHẢO}

1. WHO. Prehospital trauma care systems. 2005

2. Naseef Abdullah, Colleen Saunders, Michael McCaul, Peter Nyasulu. A retrospective study of the pre-hospital trauma burden managed by the Western Cape Government Emergency Medical Services. SAJPEC | http://www.journals.ac.za/ index.php/sajpec/ | June 2021 Vol. 2(1): 18-26.

3. JICA. Báo cáo thực trạng hệ thống sơ cấp cứu tại Việt Nam giai đoañ 2007-2009. 2009.

4. Cực quản lý mối trường $Y$ tế Viêt Nam. Thống kể tử vong do tai nạn thương tích. 2014 - 2016. 
5. Nguyễn Đức Chính, Đỗ Mai Dung, Trân Tuấn Anh, Ngô Thị Huệ. Tình hình tai nạn giao thông qua các trường hợp cấp cứu tại Bệnh viện Việt Đức 2016 - 2018. Tạp chí Y học Dự phòng, 2019, 29(8): 135-140.

6. Lương Mai Anh, Nguyễn Thị Thu Huyên, Nguyên Bích Hải. Kêt quả triển khai chăm sóc chấn thương trước viện tại Thừa Thiên Huế giai đoạn 2012-2013. Tạp chí Giao thông vận tải, 2016, 57: $134-137$

7. Douglas $\mathbf{N}$, Leverett J, Paul J, Gibson $\mathbf{M}$, Pritchard J, Brouwer K, Edwards E, Carew J, Donovan J, Bourke E, Smith E. Performance of First Aid Trained Staff using a Modified START Triage Tool at Achieving Appropriate Triage Compared to a Physiology-Based Triage Strategy at Australian Mass Gatherings. Prehosp Disaster Med. 2020 Apr;35(2):184-188.

\title{
ĐÁNH GIÁ CHỨC NĂNG THẤT TRÁI TRƯớC VÀ SAU PHẪU THUÂT BẮC CẦU CHỦ VÀNH Ở BÊ̂NH NHÂN ĐÁI THÁO ĐƯỜNG TYPE 2
}

\author{
Vũ Thị Lan', Nguyễn Quang Tuấn², Vũ Quỳnh Nga'
}

\section{TÓM TẮT}

Mục Tiêu: Đánh giá chức năng thất trái bằng siêu âm tim trước và sau phấu thuật bắc câuu chủ vành ở bệnh nhân đái tháo đường type2. Đối tượng phương pháp nghiên cứu: Nghiên cứu mổ tả cắt ngang trên 46 bệnh nhân đái tháo đường type 2 được phẫu thuật bắc cầu chủ vành đơn thuần từ $8 / 2020$ đến $8 / 2021$ tai bênh viên Tim Hà Nôi. Kết quả: Tuổi trung bình $6 \dot{6} \pm 8,73$; tỷ lệ nam/nữ là 2,83/1;43,5\% bênh nhân hút thuốc lá; tỷ lê đau ngực gắp $69,6 \%$ và NYHA III - IV chiếm $28,6 \%$.Kết quả siêu ẩm tim: Tỉ lệ rối loan vận đông vùng trước và sau phẫu thuật là $56,5 \%$ và $43,5 \%$; số vùng rối loạn trước và sau phẫu thuât là $3,52 \pm 5,39$ và $2,54 \pm 4,87$.Kết quả siêu âm tim ở nhóm $\mathrm{EF}<50 \%$ trước phấu thuật: Dd trước và sau phẫu thuật là $53.3 \pm 7,12 \mathrm{~mm}$ và $50,3 \pm 6,93 \mathrm{~mm}$. Ds trước và sau phẩu thuật là $40,4 \pm 8,44 \mathrm{~mm}$ và $36,8 \pm$ $8,05 \mathrm{~mm}$, Vd trước và sau phẫu thuật là $142,2 \pm 48,77 \mathrm{ml}$ và $124,2 \pm 38,9 \mathrm{ml}$. Vs trước và sau phẫu thuật là $77 \pm 42,13 \mathrm{ml}$ và $61,1 \pm 29,47 \mathrm{ml}$, LVMI là $135,5 \pm 44,61$ gram và 117,4 $\pm 30,17 \mathrm{gram}, \mathrm{EF}$ trước và sau phấu thuật là $39,22 \pm 8,4 \%$ và $45,83 \pm$ 13,39\% có sự cải thiện có ý nghĩa thống kê các thông số siêu âm: ĖF tăng lền đáng kể trong khi thể thể tích buồng tim, kích thước buồng tim và khối lượng cơ thất trái giảm. Riêng Nhóm EF bình thường: các thông số giảm nhưng không có ý nghĩa thống kê. Kết luân: Phẫu thuật bắc cầu chủ vầnh cải thiện đáng kể chức năng thất trái ngay sau phẫu thuật ở nhóm có EF thấp trước phẫu thuật.

Tử khóa: Pिẫu thuật bắc cầu chủ vành, đái tháo đường, chức năng thất trái.

Tứ viết tắt: $\mathrm{Dd}$ : đường kính thất trái cuối tâm trương, Ds: đường kính thất trái cuối tâm thu, EF: phân suất tống máu thất trái, RLCNTTr: rối loạn chức năng tâm trương thất trái, NYHA: phân độ khó thở

\footnotetext{
${ }^{1}$ Bệnh viện Tim Hà Nội,

Bênhh viện Bạch Mai.

Chịu trách nhiệm chính: Vũ Thị Lan

Email: lanvu1987@yahoo.com

Ngày nhận bài: 13.9.2021

Ngày phản biện khoa học: 2.11.2021

Ngày duyệt bài: 15.11.2021
}

theo hội tim mạch New York, Vd: thể tích thất trái cuối tâm trương, Vs: thể tích thất trái cuối tâm thu; LVMI: chỉ số khối cơ thất trái, TB: trung bình

\section{SUMMARY \\ EVALUATION OF LEFT VENTRICULAR FUNCTION BEFORE AND AFTER CORONARY ARTERY BYPASS GRAFT SURGERY IN PATIENTS WITH TYPE 2 DIABETES \\ Objectives: Evaluation of left ventricular function} by echocardiography before and after coronary artery bypass graft surgery in patients with type 2 diabetes. Subjects and methods: a cross-sectionnal observation study in 46 patients with type 2 diabetes were included coronary artery bypass graft surgery from $8 / 2020$ to $8 / 2021$ at Hanoi Heart Hospital. Results: Mean age $66 \pm 8.73$; male/female ratio is $2.83 / 1 ; 43.5 \%$ of patients smoke; the rate of chest pain was $69.6 \%$ and NYHA III - IV accounted for $28.6 \%$. Echocardiographyresult: The number of disturbance areas before and after surgery were $3.52 \pm 5.39$ and $2.54 \pm 4.87$. Echocardiography resultin the group with preoperative $\mathrm{EF}<50 \%$ : Dd before and after surgery were $53.3 \pm 7,12 \mathrm{~mm}$ and $50,3 \pm$ $6,93 \mathrm{~mm}$. Ds before and after surgery were 40,4 $8,44 \mathrm{~mm}$ and $36,8 \pm 8,05 \mathrm{~mm}$, Vd before and after surgery were $142,2 \pm 48,77 \mathrm{ml}$ and $124,2 \pm 38,9 \mathrm{ml}$. Vs before and after surgery were $77 \pm 42,13 \mathrm{ml}$ and 61,1 $\pm 29,47 \mathrm{ml}$, LVMI before and after surgery were $135,5 \pm$ 44,61 grams and 117,4 $\pm 30,17$ grams, EF before and after surgery were $39,22 \pm 8,4 \%$ and $45,83 \pm 13,39 \%$ There was a statistically significant improvement in ultrasound parameters in the group with preoperative $\mathrm{EF}<50 \%$ : EF increased significantly while cardiac chamber volume, chamber size and left ventricular muscle mass decreased. Particularly in the EF group, the parameters decreased but there was no statistical significance. Conclusion: Coronary bypass surgery significantly improved left ventricular function immediately after surgery in the group with low EF before surgery.

Keywords: Coronary artery bypass grafting, diabetes, left ventricular function 